\title{
Dabigatran-induced Esophageal Ulcer at a Natural Constriction
}

\author{
Sho Sasaki ${ }^{1}$, Jun Nishikawa ${ }^{2}$, Atsushi Goto ${ }^{3}$ and Isao Sakaida ${ }^{3}$
}

Key words: dabigatran, esophageal ulcer

(Intern Med 58: 757-758, 2019)

(DOI: 10.2169/internalmedicine.1618-18)

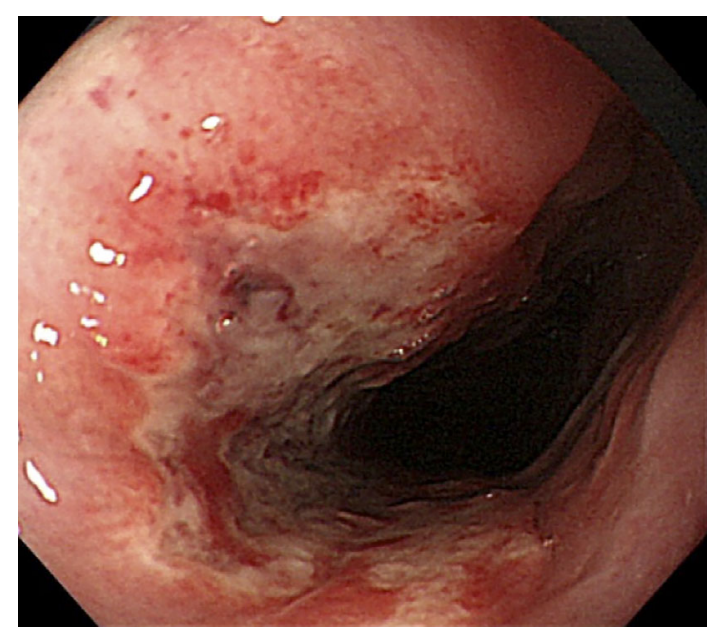

Picture 1.

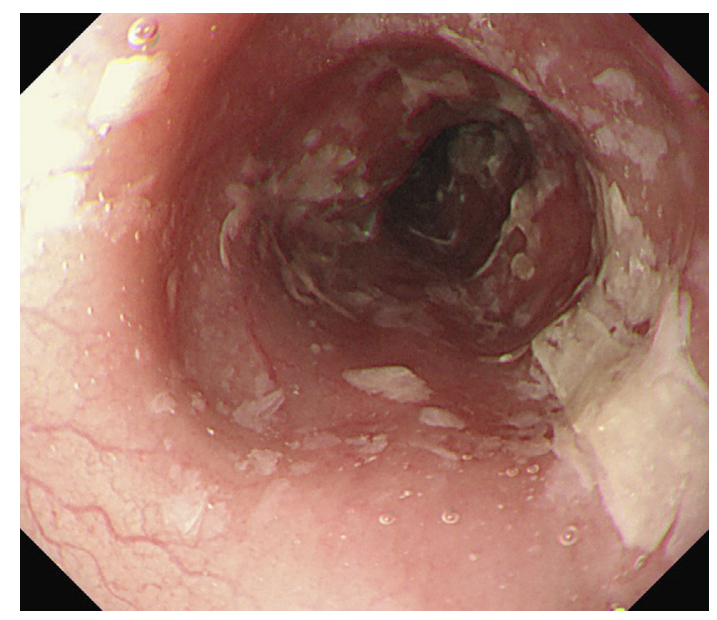

Picture 3.

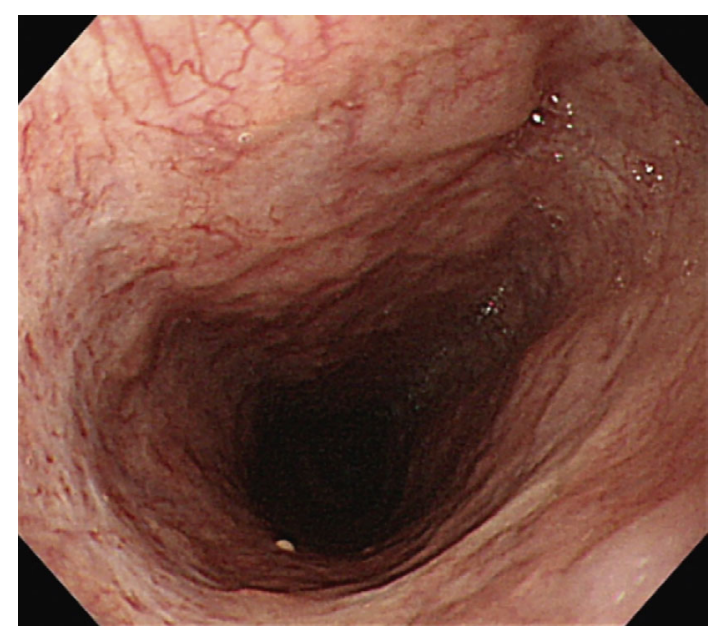

Picture 2.

A 48-year-old man with atrial fibrillation who had been taking dabigatran for 12 months experienced chest discomfort. Esophagogastroduodenoscopy (EGD) revealed an ulcerative lesion in the thoracic esophagus that was compressed by the left bronchus, which healed spontaneously two months later. Five months thereafter, he felt throat discomfort. EGD revealed a semicircular ulcer at the esophageal orifice (Picture 1). The patient usually took dabigatran without water, which allowed the dabigatran to remain abnormally long in the natural constriction of the esophagus, as evidenced by progression of local mucosal injury. After we instructed the patient on proper dabigatran administration, the ulcer healed and has not relapsed for 12 months (Picture 2). Tartaric acid excipient in dabigatran possibly caused the mucosal injury. Characteristics of dabigatraninduced esophagitis are reported as longitudinally sloughing casts in the distal esophagus (Picture 3) $(1,2)$, but our patient's ulcer was located in the esophageal orifice. Clinicians

${ }^{1}$ Department of Gastroenterology, Tokuyama Central Hospital, Japan, ${ }^{2}$ Department of Laboratory Science, Yamaguchi University Graduate School of Medicine, Japan and ${ }^{3}$ Department of Gastroenterology and Hepatology, Yamaguchi University Graduate School of Medicine, Japan Received: May 31, 2018; Accepted: August 2, 2018; Advance Publication by J-STAGE: October 17, 2018 Correspondence to Dr. Sho Sasaki, yudaon@yahoo.co.jp 
need to instruct patients to take dabigatran with sufficient water in order to avoid ulcer recurrence.

The authors state that they have no Conflict of Interest (COI).

\section{References}

1. Okada M, Okada K. Exfoliative esophagitis and esophageal ulcer induced by dabigatran. Endoscopy 44: E23-E24, 2012.

2. Toya Y, Nakamura S, Tomita K, Matsuda N, Abe K. Dabigatraninduced esophagitis: The prevalence and endoscopic characteristics. J Gastroenterol Hepatol 31: 610-614, 2016.

The Internal Medicine is an Open Access journal distributed under the Creative Commons Attribution-NonCommercial-NoDerivatives 4.0 International License. To view the details of this license, please visit (https://creativecommons.org/licenses/ by-nc-nd/4.0/).

(C) 2019 The Japanese Society of Internal Medicine Intern Med 58: 757-758, 2019 